\title{
The Effects of Old Age on Hepatic Stellate Cells
}

\author{
Alessandra Warren, ${ }^{1}$ Victoria C. Cogger, ${ }^{1}$ Robin Fraser, ${ }^{2}$ Laurie D. DeLeve, ${ }^{3}$ \\ Robert S. McCuskey, ${ }^{4}$ and David G. Le Couteur ${ }^{1}$ \\ ${ }^{1}$ Centre for Education and Research on Ageing, Concord Hospital and the ANZAC Research Institute, \\ The University of Sydney, Sydney NSW 2139, Australia \\ ${ }^{2}$ Department of Pathology, University of Otago and Christchurch Hospital, Christchurch 8140, New Zealand \\ ${ }^{3}$ Division of Gastrointestinal and Liver Diseases and the USC Research Center for Liver Diseases, Keck School of Medicine, \\ University of Southern California, Los Angeles, CA 90033, USA \\ ${ }^{4}$ Department of Cell Biology and Anatomy, College of Medicine, The University of Arizona, Tucson, AZ 85721, USA
}

Correspondence should be addressed to David G. Le Couteur, david.lecouteur@sydney.edu.au

Received 28 October 2010; Revised 7 February 2011; Accepted 22 March 2011

Academic Editor: Dmitri Svistounov

Copyright (C) 2011 Alessandra Warren et al. This is an open access article distributed under the Creative Commons Attribution License, which permits unrestricted use, distribution, and reproduction in any medium, provided the original work is properly cited.

Aging is associated with marked changes in the hepatic sinusoid, yet the effect of old age on hepatic stellate cells (HSC) has not been well described. Transmission electron microscopy and immunohistochemistry were used to study the effects of aging on HSC in livers from rats (3-4 mths versus 24-27 mths) and mice (2-3 mths versus 20-22 mths). Desmin-positive HSC doubled in old age in both mice and rats. Alpha-smooth muscle actin- $(\alpha \mathrm{SMA}-)$ positive cells did not increase significantly and remained only a small percentage of desmin-positive cells. Electron microscopy revealed that old age is associated with HSC that have a substantial increase in the number of lipid droplets which are larger in diameter. There was also a marked increase of HSC that protruded into the sinusoidal lumen in old mice. In conclusion, old age is associated with hyperplasia of HSC that are not activated and are engorged with lipid droplets.

\section{Introduction}

Old age is associated with various changes in the hepatic sinusoid. These include thickening of the liver sinusoidal endothelial cell (LSEC) and loss of endothelial fenestrations, deposition of perisinusoidal basal lamina and collagen, and upregulation of proteins not usually seen in the young healthy liver such as von Willebrands factor and collagen [1, 2]. This has been termed age-related pseudocapillarisation. In addition, there are increased numbers of basally activated Kupffer cells (KC) that respond poorly to immune challenges [3]. As well as the LSEC and KC, the other main cell in the hepatic sinusoid is the hepatic stellate cells (HSC).

The HSC (or Ito cell) is a pericyte that resides in the extracellular space of Disse and has long cytoplasmic extensions that wrap around the LSECs. HSC contain many lipid droplets that are rich in vitamin $\mathrm{A}$, which generates characteristic autofluorescence. In the early phases of many chronic liver diseases, HSC become activated and contribute to the fibrosis by producing extracellular matrix components such as collagen. In this activated state, HSC lose their lipid droplets and become myofibroblastic in appearance and stain positive for $\alpha$-smooth muscle actin $(\alpha \mathrm{SMA})[4,5]$. It is unknown whether HSC contribute to the mild perisinusoidal fibrosis seen in old age. Furthermore, a recent study has shown that LSECs are involved in the regulation of activation of HSC [6] which raises the possibility that the age-related changes in the LSEC might impact on HSCs.

There have been only a few reports of the effects of old age on HSC. An early study found that HSC had more and larger lipid droplets in old rats [7], a finding that we also described more recently in nonhuman primates $[8]$ and mice $[9,10]$. Here, we investigated whether old age is associated with any change in the number or activation of HSC and quantified the changes in lipid droplets that accumulate in HSC in old age.

\section{Methods}

2.1. Animals. Rats were F344 aged 3-6 mths and $24-27 \mathrm{mths}$ ( $n=5$ old, $n=6$ young) obtained from the National Institute 
TABLE 1: Transmission electron microscopic analyses of the effects of old age on HSC.

\begin{tabular}{|c|c|c|c|c|}
\hline & $\begin{array}{c}\text { Number of lipid } \\
\text { droplets/HSC }\end{array}$ & $\begin{array}{c}\text { Number of lipid } \\
\text { droplets/HSC with } \\
\text { nucleus }\end{array}$ & $\begin{array}{c}\text { Diameter of lipid } \\
\text { droplets in HSC }\left(\mu \mathrm{m}^{2}\right)\end{array}$ & $\begin{array}{l}\text { HSC protruding into } \\
\text { sinusoidal lumen } \\
\text { (number and \% of tota } \\
\text { HSC) }\end{array}$ \\
\hline \multicolumn{5}{|r|}{ 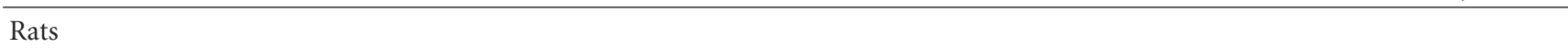 } \\
\hline Young & $6.76 \pm 4.51$ & $6.91 \pm 4.59$ & $1.08 \pm 0.44$ & $8(7 \%)$ \\
\hline old & $9.17 \pm 6.35^{*}$ & $10.09 \pm 6.38^{*}$ & $1.20 \pm 0.50^{*}$ & $10(10 \%)$ \\
\hline \multicolumn{5}{|l|}{ Mice } \\
\hline Young & $2.41 \pm 1.24$ & $2.41 \pm 1.24$ & $1.83 \pm 0.87$ & $3(5 \%)$ \\
\hline Old & $6.33 \pm 3.55^{*}$ & $6.77 \pm 4.31^{*}$ & $3.15 \pm 2.19^{*}$ & $29(51 \%)^{*}$ \\
\hline
\end{tabular}

${ }^{*} P<.05$.

of Aging (Baltimore, USA). Mice were B10 aged 2-3 mths and 20-22 mths ( $n=3$ in each group) that were maintained at the Centenary Institute (Sydney, Australia) in specific pathogen-free conditions and fed standard laboratory chow. The study was approved by the Sydney Southwest Area Health Service Animal Welfare Committee. After ketamine/ xylazine anesthesia, liver tissue was harvested and fixed with paraformaldehyde for immunohistochemistry or with glutaraldehyde for transmission electron microscopy.

2.2. Transmission Electron Microscopy. Two blocks of glutaraldehyde-fixed liver tissue from each animal were cut and studied using a Philips CM10 transmission electron microscope. Approximately $20 \mathrm{HSC}$ for each animal were photographed at 2,600 magnification and subsequently analyzed using ImageJ (http://rsbweb.nih.gov/ij/). The larger diameter of each lipid droplet contained in the cell cytoplasm and the area of each cell was determined. The number of lipid droplets per HSC was also analysed only in those sections where the HSC contained a nucleus in an attempt to compensate for the possibility that the sections were taken in different planes. In total we analyzed 680 droplets and 108 HSC from young rats, 806 droplets and 98 HSC from old rats, 170 droplets and 59 HSC from young mice, and 351 droplets and 57 HSC from old mice.

2.3. Immunohistochemistry. Staining was performed for desmin, which is a marker of HSC, and $\alpha \mathrm{SMA}$, which is a marker of activated HSC [11]. Liver specimens embedded in paraffin blocks were used. Sections from each block were stained for desmin (NCL-DER11 Novocastra 1:200) and $\alpha$ SMA (NCL-SMA Novocastra 1:200). Rat liver sections were processed using an automatic IHC Leica staining protocol on Leica Bond Polymer, Refine Detection (DS9800) with Bond DAB enhancer $30 \mathrm{~mL}$ (AR9432). EDTA buffer $\mathrm{pH} 9$ was used for the antigen retrieval step for $30 \mathrm{~min}$ for the detection of desmin. Mice sections were stained manually. For desmin visualization, slides were incubated for $10 \mathrm{~min}$ in microwave with the same antigen retrieval buffer (EDTA pH 9). Sections were pretreated with $0.3 \%$ hydrogen peroxide for $20 \mathrm{~min}$ in PBS and avidin-biotin blocking solutions and then incubated with primary antibodies over night at $4^{\circ} \mathrm{C}$. Antimouse biotinylated secondary antibody (1:150 Sigma, St. Louis, MO) was applied for $40 \mathrm{~min}$ at room temperature followed by peroxidase-conjugated streptavidin (40 min, 1:50 Sigma, St. Louis, MO). Peroxidase activity was visualized using 3,3'-diaminibenzidine. Three representative images for each section were taken at 200 magnification and analyzed using the software ImageJ. For each photograph, parenchymal area was calculated (large vessels were excluded) and desmin- and $\alpha$ SMA-positive nucleated cells were manually counted, and results were adjusted for $0.5 \mathrm{~mm}^{2}$ area.

2.4. Statistics. The results are expressed as average \pm standard deviation and comparisons performed using parametric and nonparametric, two-tailed Students $t$-test, depending upon the Schapiro Wilk test for normality (SigmaPlot v11).

\section{Results}

Table 1 shows the results of the transmission electron microscopic analysis and Figures 1 and 2 show representative pictures of stellate cells in young and old rats and mice. There were changes in HSC with old age in both rats and mice, although the changes were more dramatic in the mice. With old age, the number of lipid droplets per HSC increased, more so in mice. In addition, the average diameter of the lipid droplets increased in both the rats and mice, again more marked in the mice.

The frequency distribution of the diameter of the lipid droplets is shown in Figure 3. There appeared to be a normal distribution of the diameter of the lipid droplets in young animals, and the droplets were larger in mice than in rats. In old age, the distribution was skewed to the right with an appreciable number of much larger droplets.

Transmission electron microscopy also revealed that there was an increase in the percentage and number of enlarged HSC that resulted in protrusion of the endothelial lining into the sinusoidal lumen in old mice, but not in old rats.

Table 2 shows the results of the immunohistochemistry analysis and Figures 4 and 5 show representative pictures of desmin and $\alpha$ SMA staining in livers from young and old rats and mice. HSC were more numerous in mice than rats. With 


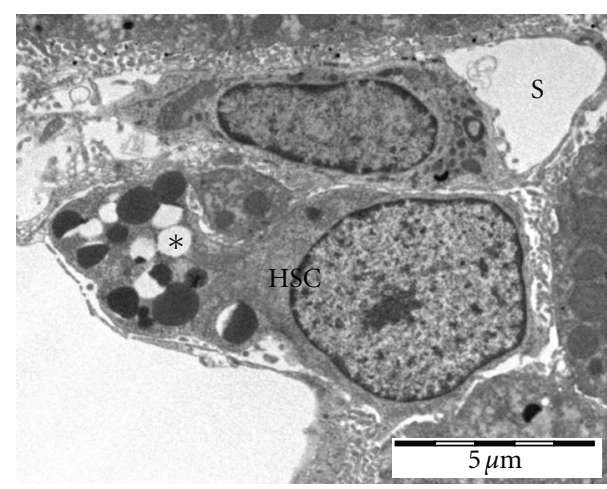

(a)

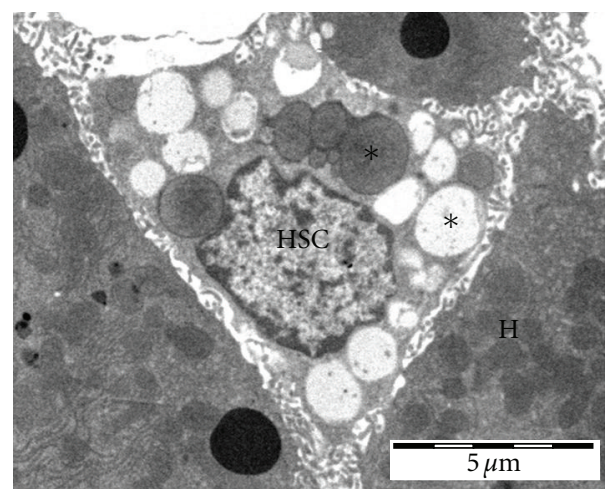

(c)

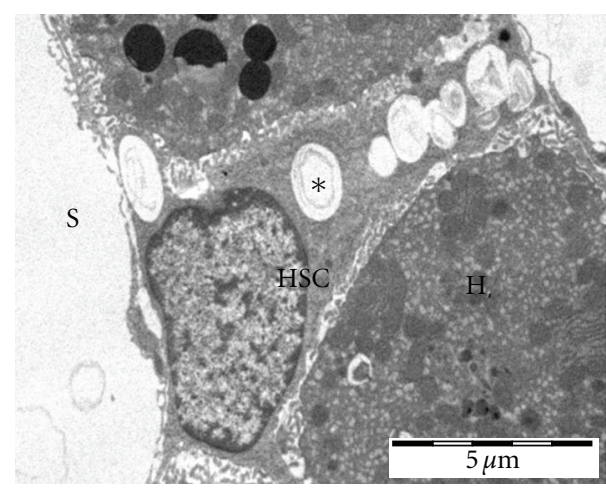

(b)

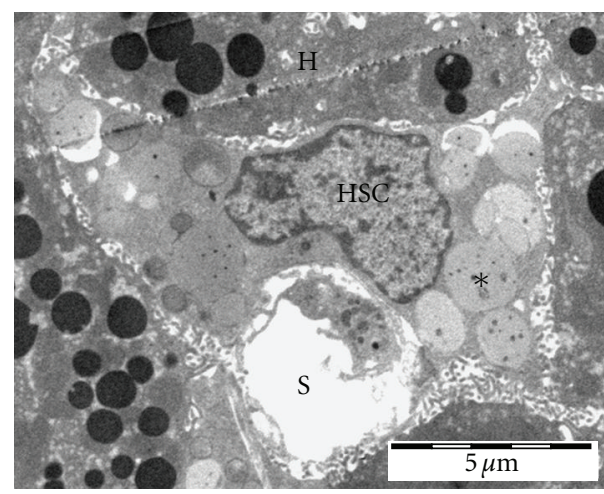

(d)

Figure 1: Representative transmission electron micrographs of HSC (HSC) from young (a,b) and old rats (c,d). Hepatic stellate cell, HSC; sinusoidal lumen, S; hepatocyte, H; lipid droplets*.

old age, there was an approximate doubling of the numbers of HSC. Activated HSC as determined by $\alpha$ SMA represented only a very small percentage of total HSC. Although there was an increase in $\alpha \mathrm{SMA}$-positive cells with old age in both rats and mice, this was not statistically significant nor did it represent a substantive change in the fraction of HSC that is activated. There was a small zonal variation in $\alpha$ SMA staining which was more intense in zone 2 (mid zone), but age did not have any impact on this distribution.

\section{Discussion}

Old age is associated with an increase in the number of HSC and and in the size and number of the lipid droplets that they contain, but no change in their activation status. Table 3 shows the results of all other studies that we could only find that make any mention of the effect of old age on HSC. There have been five other studies involving rats [7, 12], baboons [8], and mice $[9,10]$ that described changes in HSC lipid droplets in old age. In our study, we quantified these changes. In old age, there was an increase in the number of droplets per HSC by about $30 \%$ in rats and $250 \%$ in mice. The diameter of the droplets increased by about $10 \%$ in rats and $35 \%$ in mice. Lipid droplets in HSC contain about $80 \%$ of all retinoids in the body (vitamin $\mathrm{A}$ and
TABLE 2: Results of immunohistochemical study of the effects of old age on HSC.

\begin{tabular}{lcc}
\hline & $\begin{array}{c}\text { Desmin staining } \\
(\text { number of positive } \\
\text { HSC/0.5 } \mathrm{mm}^{2} \text { ) }\end{array}$ & $\begin{array}{c}\alpha \text { SMA staining } \\
(\text { number of positive } \\
\left.\text { HSC/0.5 } \mathrm{mm}^{2}\right)\end{array}$ \\
\hline Rats & \\
$\quad$ Young & $21.3 \pm 15.1$ & $0.6 \pm 1.0$ \\
Old & $45.5 \pm 23.5^{*}$ & $2.8 \pm 3.8$ \\
Mice & & $0 \pm 0$ \\
Young & $66.1 \pm 28.8$ & $1.1 \pm 1.8$ \\
Old & $134.0 \pm 55.6^{*}$ & \\
\hline
\end{tabular}

${ }^{*} P<.05$.

its metabolites) mostly in the form of retinyl palmitate [4]. In addition, HSC lipid droplets contain triglyceride, cholesteryl ester, cholesterol, phospholipids, and free fatty acids. Retinyl ester and triglyceride are present at similar concentrations and together account for three-quarters of the total lipid in HSC lipid droplets [13]. In humans, plasma retinoids do not decrease with old age $[14,15]$, however, the postprandial levels are abnormal and consistent with reduced mobilization of vitamin A from the liver [15]. Vollmar et al. [16] 


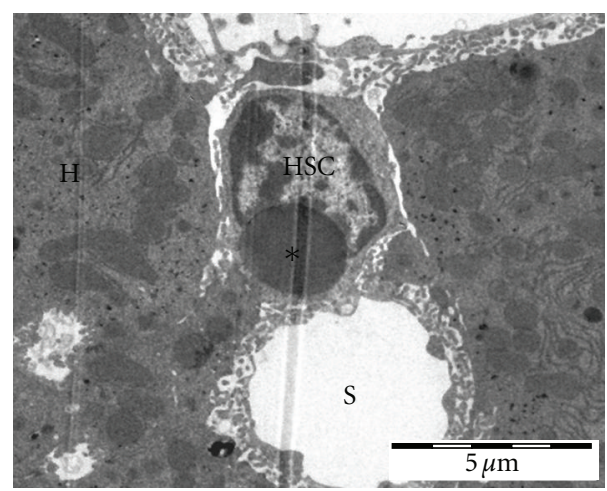

(a)

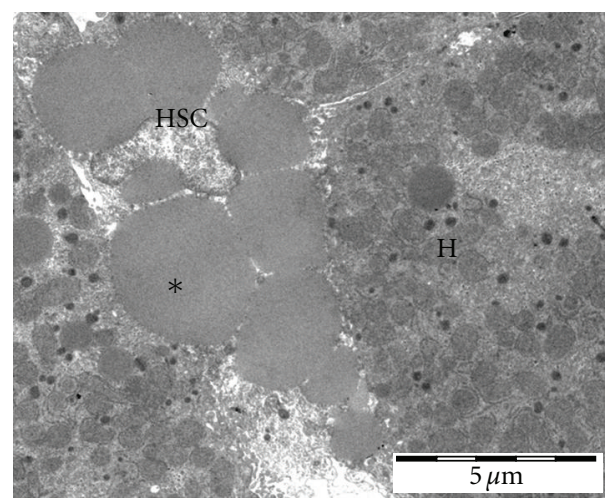

(c)

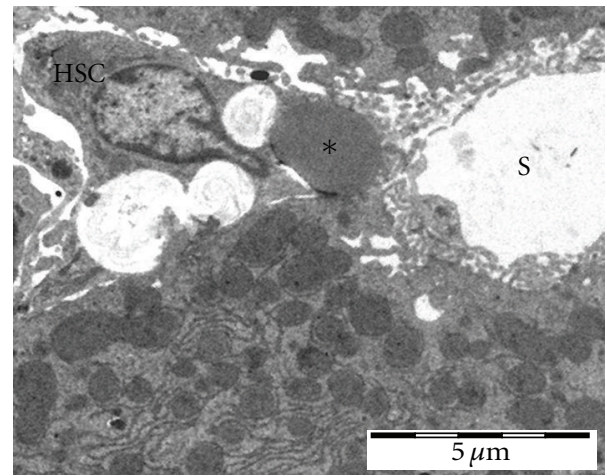

(b)

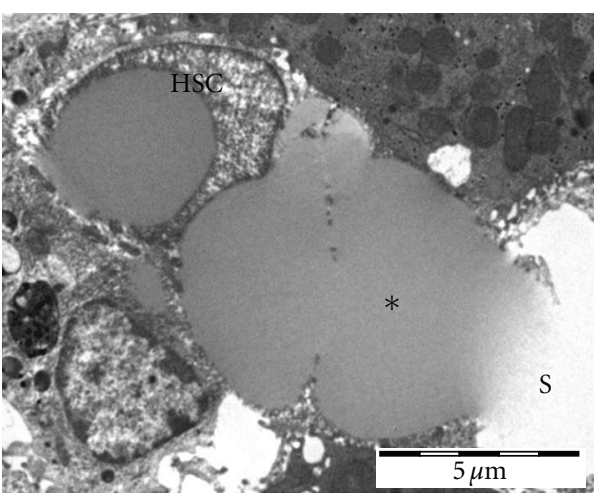

(d)

Figure 2: Representative transmission electron micrographs of HSC (HSC) from young (a,b) and old mice (c,d). Hepatic Stellate Cell HSC; Sinusoidal lumen S; Hepatocyte H; Lipid droplets*.

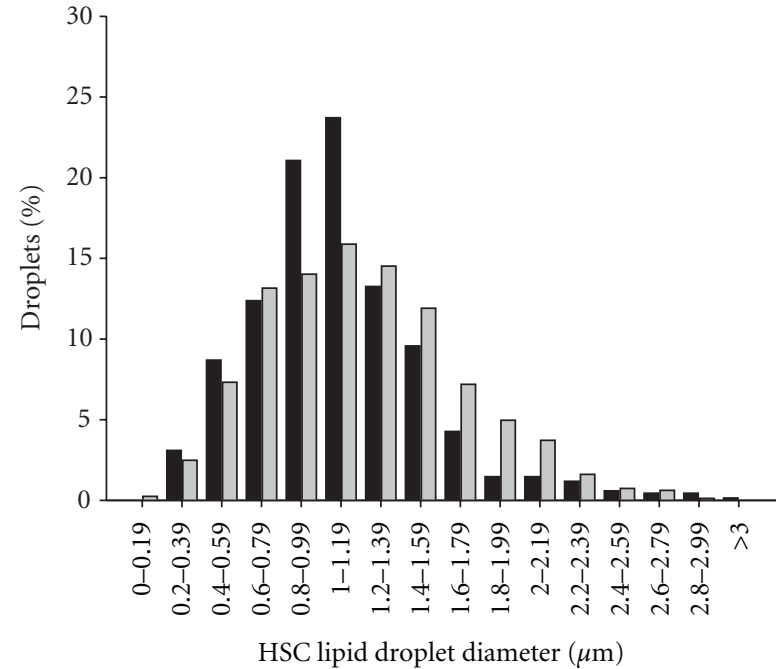

(a)

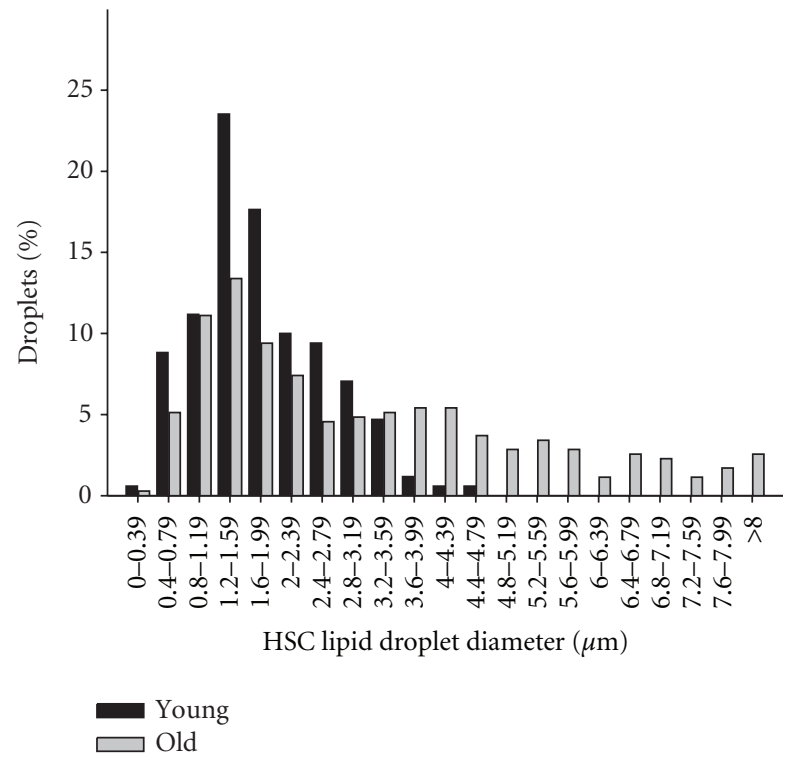

(b)

FIGURE 3: Frequency distribution of the diameter of the lipid droplets in HSC from rats (a) and mice (b). In both rats and mice, the distribution was skewed to the right in old age. 


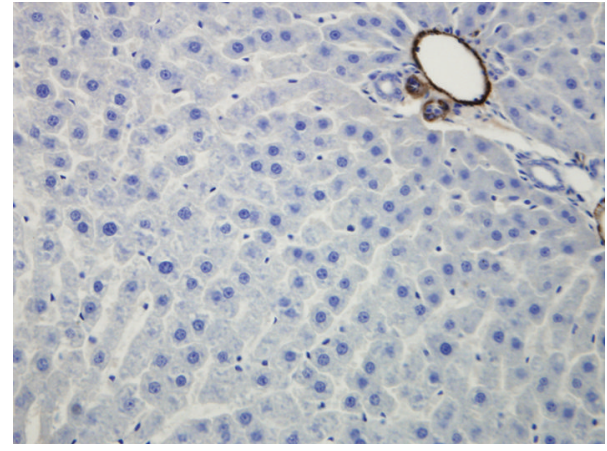

(a)

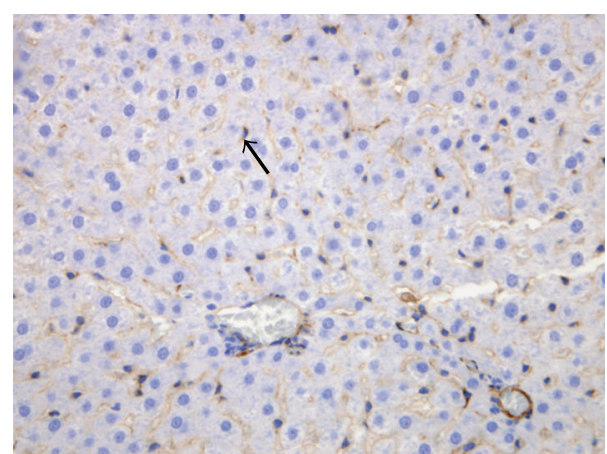

(c)

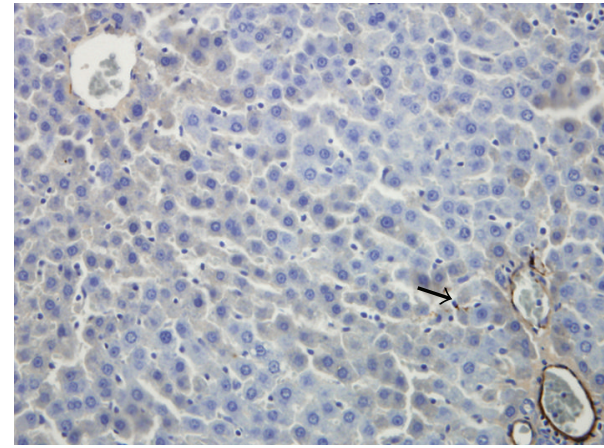

(b)

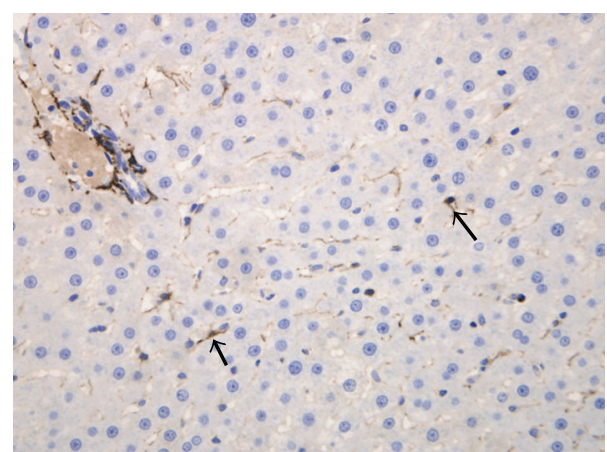

(d)

FIGURE 4: Representative immunohistochemistry from rat livers showing SMA in young (a) and old (b) rats, and desmin immunostaining in young $(\mathrm{c})$ and old $(\mathrm{d})$ rats (magnification $\times 200)$.

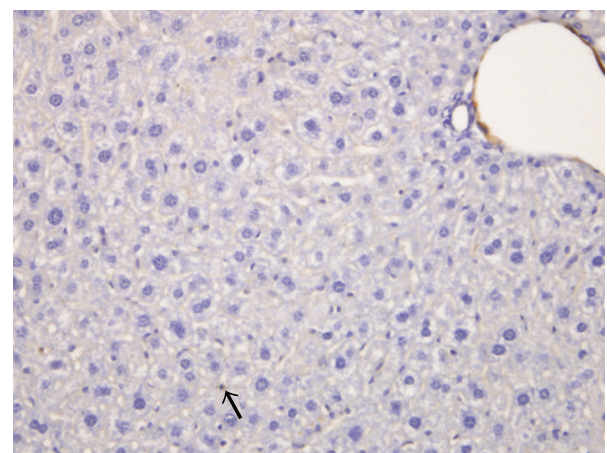

(a)

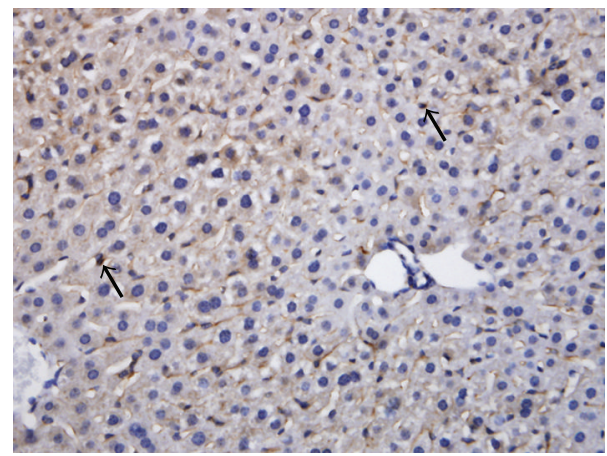

(c)

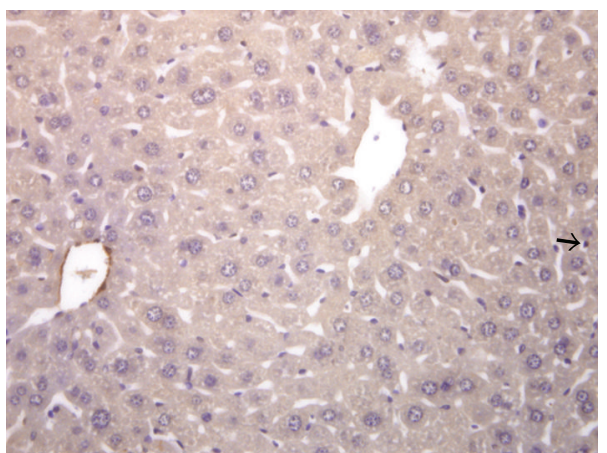

(b)

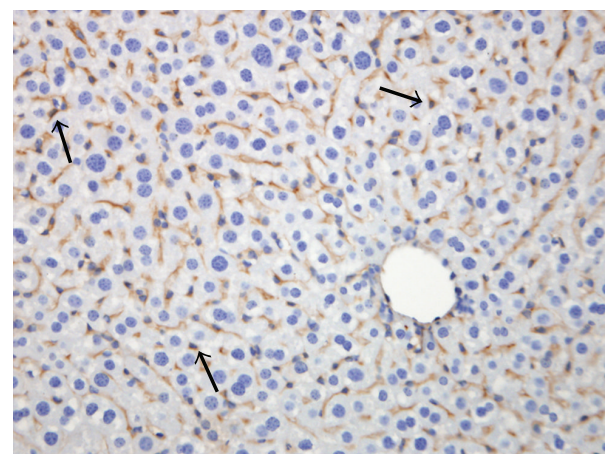

(d)

FIGURE 5: Representative immunohistochemistry from mice livers showing SMA in young (a) and old (b) mice, and desmin immunostaining in young $(\mathrm{c})$ and old $(\mathrm{d})$ mice (magnification $\times 200)$. 
TABLE 3: The results of previous studies where the effect of old age on HSC was reported.

\begin{tabular}{|c|c|c|c|c|}
\hline \multicolumn{2}{|c|}{ Citation Species } & \multirow{2}{*}{$\begin{array}{c}\text { Morphology } \\
\uparrow \text { lipid } \\
\text { droplets }\end{array}$} & \multirow{2}{*}{$\begin{array}{c}\text { Number } \\
\leftrightarrow\end{array}$} & \multirow{2}{*}{$\begin{array}{c}\text { Activation } \\
\text { n.d. }\end{array}$} \\
\hline [7] & Rat & & & \\
\hline$[12]$ & Rat & $\begin{array}{c}\uparrow \text { lipid } \\
\text { droplets }\end{array}$ & n.d & n.d. \\
\hline$[18]$ & Rat & n.d. & $\begin{array}{c}\uparrow(\text { from } 0.43 \text { to } \\
1.02 \% \text { of liver } \\
\text { volume, } \\
P=.075)\end{array}$ & n.d. \\
\hline$[16]$ & Rat & n.d. & $\stackrel{\uparrow}{\uparrow}$ autofluorescence & n.d. \\
\hline$[8]$ & Baboon & $\begin{array}{c}\uparrow \text { lipid } \\
\text { droplets }\end{array}$ & n.d. & $\leftrightarrow(\alpha \mathrm{SMA})$ \\
\hline [19] & Rat & n.d. & n.d. & $\leftrightarrow(\alpha \mathrm{SMA})$ \\
\hline [9] & Mouse & $\begin{array}{c}\uparrow \text { lipid } \\
\text { droplets }\end{array}$ & n.d. & n.d. \\
\hline$[10]$ & Mouse & $\begin{array}{l}\uparrow \text { lipid } \\
\text { droplets }\end{array}$ & n.d. & n.d. \\
\hline
\end{tabular}

(n.d. not done).

reported an increase in retinoid content in old rat liversa twofold increase of retinol, 32-fold increase of retinyl stearate, 53-fold increase of retinyl palmitate, and 66-fold increase of retinyl oleate. This suggests that the increase in the size and number of lipid droplets in HSC is related at least in part to an increase in retinoids in HSC. However, droplets also contain a similar amount of triglycerides, and there are reports of increased triglyceride content of old livers [17], but whether there is accumulation of triglycerides in HSC is not known.

There were increased HSC numbers in old age in both rats and mice. Previously, Enzan et al. [7] commented that there was no change in the frequency of HSC, but this study was performed using electron microscopy and no data were provided [7]. Similarly Martin et al. [18] concluded that there were no changes in HSC numbers in old age in rats. However, in their study, the volume of liver consisting of HSC increased from $0.43 \pm 0.13 \%$ in young rats to $1.0 \pm 0.24 \%$ in old rats but this did not reach statistical significance $(P=$ .075 with only 4 rats in each age group) [18]. In our study, desmin immunohistochemistry was used to determine the number of HSC present in liver. In both rats and, mice old age was associated with approximately a doubling in the numbers of desmin-positive HSC per $0.5 \mathrm{~mm}^{2}$. As such, the result is numerically consistent with that of Martin et al., [18] although our results were statistically significant. It is of interest that we have previously found an increase in the number of Kupffer cells in old age. Specifically, the number increased from $2.0 \pm 0.2$ to $5.5 \pm 0.6$ cells per $29,500 \mu \mathrm{m}^{2}$ in old age in rats [3]. The effect of old age on the numbers of the other main cell of the hepatic sinusoid, the LSEC is unknown.

Finally, we performed immunohistochemistry with $\alpha$ SMA to determine whether these HSCs are activated. Activated HSCs are characterised by loss of lipid droplets and expression of $\alpha$ SMA. The fact that we and others have noted that HSC from old animals are engorged with lipid droplets is consistent with the conclusion that HSC are not activated in old age. Likewise, we did not find any statistically significant change in $\alpha$ SMA-positive HSCs in old age. Although there was a slight increase in the number of $\alpha$ SMA-positive cells in old age, this was balanced out by the doubling in the total number of HSC so that the fraction of total HSCs that is activated remained only very small. Previously Grizzi et al. [19] found a nonsignificant increase in $\alpha \mathrm{SMA}$ in the livers of old rats, but this did not increase in response to carbon tetrachloride as was seen with young livers [19]. We also noted that $\alpha \mathrm{SMA}$ staining was not increased in the livers of old baboons [8]. The lack of activation of HSCs in old age means that it is unlikely that these cells are contributing to the mild perisinusoidal fibrosis that is seen in many species in old age [2]. Furthermore, the fact that HSCs are quiescent in old age suggests that the other changes of pseudocapillarisation seen in the aged hepatic sinusoid are unlikely to be secondary to undiagnosed chronic liver disease because this is invariably associated with activation of HSCs.

In conclusion, old age is associated with increased numbers of fat engorged, quiescent HSCs. This has implications for the effect of age on retinoid metabolism and for the mechanisms for other age-related morphological changes in the hepatic sinusoid. The increase in the percentage and number of enlarged HSCs that resulted in protrusion of the endothelial lining into the sinusoidal lumen in old mice may contribute to the reduced sinusoidal blood flow reported in aged mice [10].

\section{Acknowledgments}

The authors acknowledge the financial support of the Australian National Health and Medical Research Council, supported in part by NIH Grant DK66423 to L. D. Deleve and NIH AG26582 to R. S. McCuskey, Canterbury Medical Research Society of New Zealand and the Ageing and Alzheimer's Research Foundation of the University of Sydney.

\section{References}

[1] D. G. Le Couteur, V. C. Cogger, A. M. A. Markus et al., "Pseudocapillarization and associated energy limitation in the aged rat liver," Hepatology, vol. 33, no. 3, pp. 537-543, 2001.

[2] D. G. Le Couteur, A. Warren, V. C. Cogger et al., "Old age and the hepatic sinusoid," Anatomical Record, vol. 291, no. 6, pp. 672-683, 2008.

[3] S. N. Hilmer, V. C. Cogger, and D. G. Le Couteur, "Basal activity of kupffer cells increases with old age," Journals of Gerontology, vol. 62, no. 9, pp. 973-978, 2007.

[4] H. Senoo, "Structure and function of hepatic stellate cells," Medical Electron Microscopy, vol. 37, no. 1, pp. 3-15, 2004.

[5] H. Senoo, N. Kojima, and M. Sato, "Vitamin a-storing cells (stellate cells)," Vitamins and Hormones, vol. 75, pp. 131-159, 2007.

[6] L. D. DeLeve, X. Wang, and Y. Guo, "Sinusoidal endothelial cells prevent rat stellate cell activation and promote reversion to quiescence," Hepatology, vol. 48, no. 3, pp. 920-930, 2008. 
[7] H. Enzan, T. Saibara, H. Ueda et al., "Ultrastructural observation of Ito cells in the aged rats," in Cells of the Hepatic Sinusoid, E. Wisse, D. L. Knook, and R. S. McCuskey, Eds., pp. 226-229, Kupffer Cell Foundation, Leiden, The Netherlands, 1991.

[8] V. C. Cogger, A. Warren, R. Fraser, M. Ngu, A. J. McLean, and D. G. Le Couteur, "Hepatic sinusoidal pseudocapillarization with aging in the non-human primate," Experimental Gerontology, vol. 38, no. 10, pp. 1101-1107, 2003.

[9] A. Warren, P. Bertolino, V. C. Cogger, A. J. McLean, R. Fraser, and D. G. Le Couteur, "Hepatic pseudocapillarization in aged mice," Experimental Gerontology, vol. 40, no. 10, pp. 807-812, 2005.

[10] Y. Ito, K. K. Sørensen, N. W. Bethea et al., "Age-related changes in the hepatic microcirculation in mice," Experimental Gerontology, vol. 42, no. 8, pp. 789-797, 2007.

[11] S. J. Johnson, J. E. Hines, and A. D. Burt, "Phenotypic modulation of perisinusoidal cells following acute liver injury: a quantitative analysis," International Journal of Experimental Pathology, vol. 73, no. 6, pp. 765-772, 1992.

[12] S. K. Durham, A. Brouwer, R. J. Barelds, M. A. Horan, and D. L. Knook, "Comparative endotoxin-induced hepatic injury in young and aged rats," Journal of Pathology, vol. 162, no. 4, pp. 341-349, 1990.

[13] W. S. Blaner, S. M. O’Byrne, N. Wongsiriroj et al., "Hepatic stellate cell lipid droplets: a specialized lipid droplet for retinoid storage," Biochimica et Biophysica Acta, vol. 1791, no. 6, pp. 467-473, 2009.

[14] J. Hallfrisch, D. C. Muller, and V. N. Singh, "Vitamin A and $\mathrm{E}$ intakes and plasma concentrations of retinol, $\beta$ - carotene, and $\alpha$-tocopherol in men and women of the Baltimore longitudinal study of aging," American Journal of Clinical Nutrition, vol. 60, no. 2, pp. 176-182, 1994.

[15] P. Borel, N. Mekki, Y. Boirie et al., "Comparison of the postprandial plasma vitamin A response in young and older adults," Journals of Gerontology, vol. 53, no. 2, pp. B133-B140, 1998.

[16] B. Vollmar, S. Pradarutti, S. Richter, and M. D. Menger, "In vivo quantification of ageing changes in the rat liver from early juvenile to senescent life," Liver, vol. 22, no. 4, pp. 330-341, 2002.

[17] E. Sanguino, R. Bejarano, M. Alegret, R. M. Sánchez, M. Vázquez-Carrera, and J. C. Laguna, "Sexual dimorphism in lipid metabolic phenotype associated with old age in SpragueDawley rats," Experimental Gerontology, vol. 39, no. 9, pp. 1295-1306, 2004.

[18] G. Martin, R. B. Sewell, N. D. Yeomans, and R. A. Smallwood, "Ageing has no effect on the volume density of hepatocytes, reticulo-endothelial cells or the extracellular space in livers of female Sprague-Dawley rats," Clinical and Experimental Pharmacology and Physiology, vol. 19, no. 7, pp. 537-539, 1992.

[19] F. Grizzi, B. Franceschini, N. Gagliano et al., "Mast cell density, hepatic stellate cell activation and TGF- $\beta$ transcripts in the aging Sprague-Dawley rat during early acute liver injury," Toxicologic Pathology, vol. 31, no. 2, pp. 173-178, 2003. 


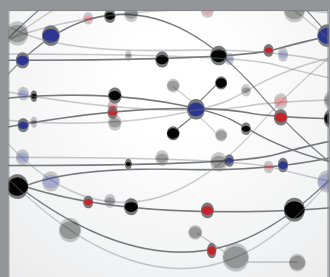

The Scientific World Journal
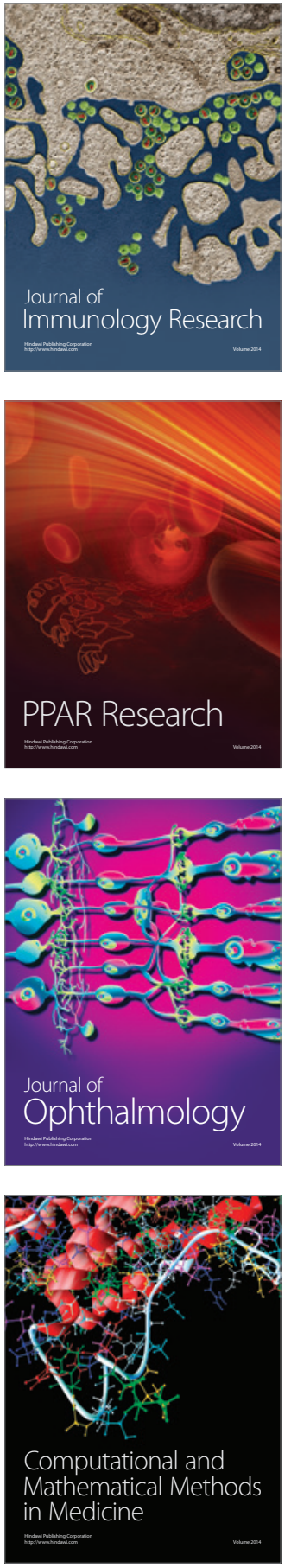

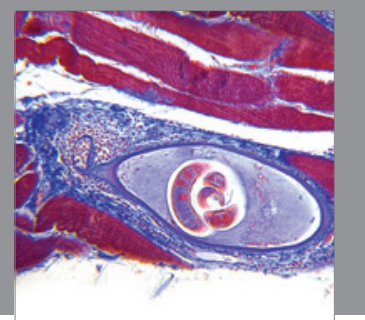

Gastroenterology

Research and Practice
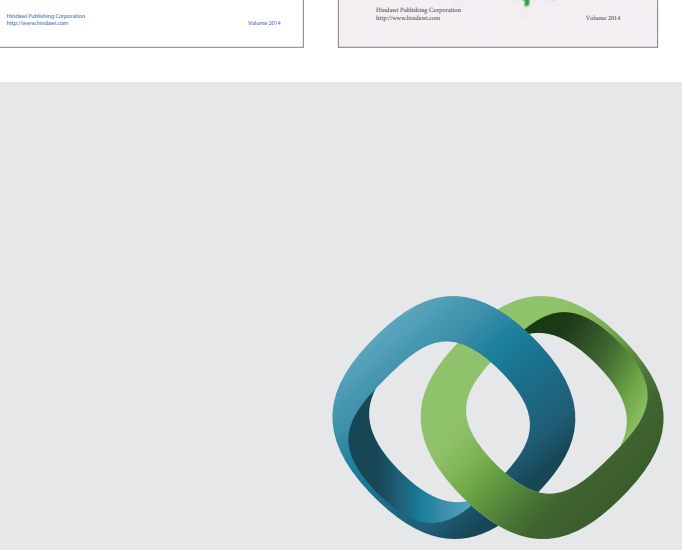

\section{Hindawi}

Submit your manuscripts at

http://www.hindawi.com
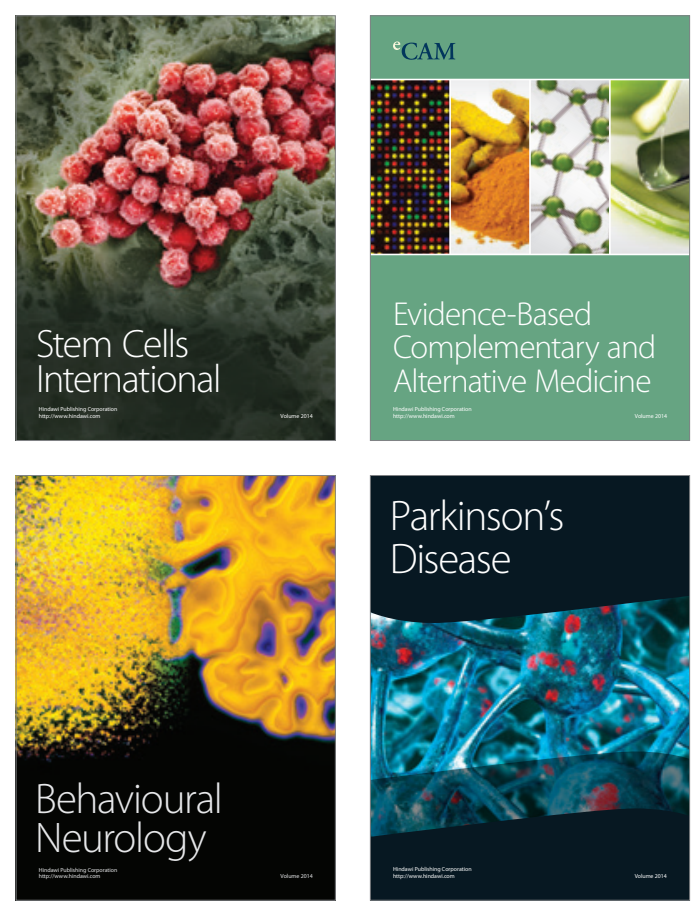

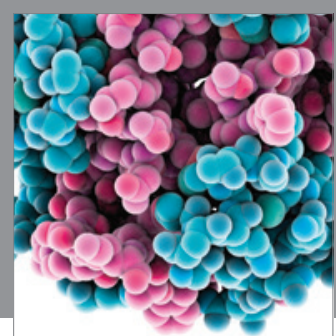

Journal of
Diabetes Research

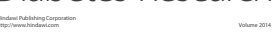

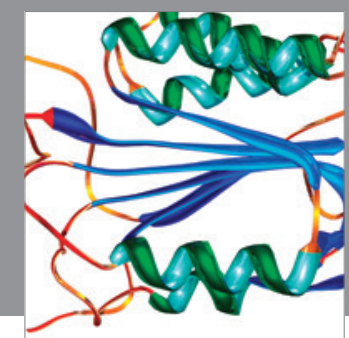

Disease Markers
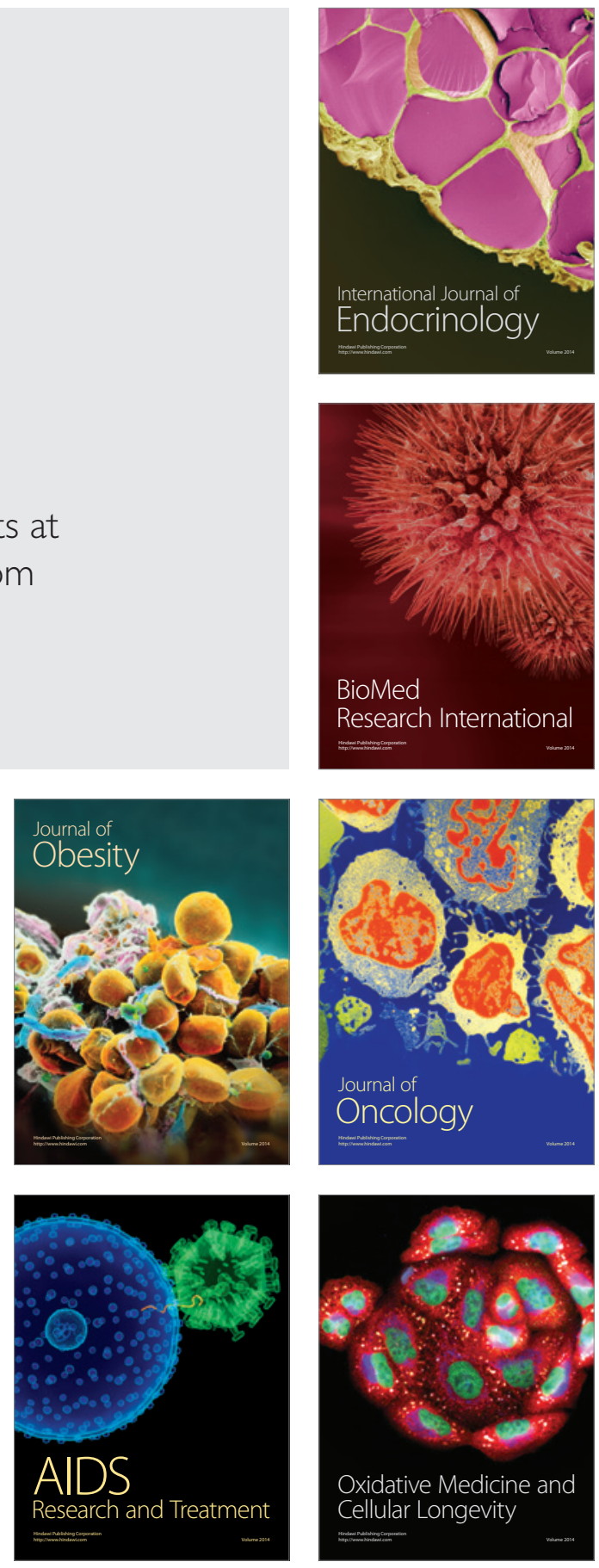